\title{
Empresários urbanos e produção do espaço residencial: condomínios-clube na Zona Sul de Natal (RN)'
}

\author{
Urban entrepreneurs and the prodution of residential space: the 'Condomínios- \\ Clube' in the South of Natal (RN)
}

Felipe Fernandes de Araúio

\section{Resumo}

As causas da localização e disseminação dos condomínios-clube em Natal, bem como as estratégias utilizadas pelos empresários urbanos para transformar a configuração residencial, são alvos da investigação que resultou neste trabalho. A principal consequência desse novo fenômeno é a ratificação do processo de segmentação urbana existente na cidade, que é um elemento essencial na relação existente entre acumulação capitalista e produção do espaço urbano. A inovação espacial pretendida pelos empresários urbanos como forma de diferenciação e aumento dos lucros gera, por outro lado, uma homogeneização do espaço residencial por meio da disseminação da tipologia condomínio-clube pela cidade. Com base em autores como Harvey e Abramo, é possível perceber a relação entre o desenvolvimento capitalista e a forma espacial urbana. Além de pesquisa bibliográfica, a metodologia utilizada baseou-se em entrevistas semiestruturadas junto aos agentes do mercado imobiliário, para abranger a relação entre a materialidade construída (estoques habitacionais) e o discurso hegemônico que orienta a configuração residencial da cidade. Como resultado, observou-se que tal discurso tende para um ponto comum, isto é, há uma convergência dos pensamentos e da prática dos agentes acerca da localização e das características de cada empreendimento. Como consequência imediata, tem-se uma homogeneização socioespacial em certos bairros em detrimento do restante da cidade.

Palavras-chave: Inovação espacial. Convenção urbana. Segmentação espacial. Condomínios-clube.

Produção do espaço.

\section{Abstract}

This paper addresses the reasons that led to the spread of 'Condomínios-clubes' in Natal, Rio Grande do Norte state, Brazil, as well as the strategies put forward by urban entrepreneurs to promote the transformation of residential space in the city. The main result of this process is the consolidation of urban segmentation, which is a crucial element in the relationship between capital accumulation and production of urban

\footnotetext{
$1_{1}$ Agradeço ao professor Dr. Márcio Moraes Valença pelas críticas, sugestões e comentários.

FFA é Bacharel em Geografia, mestre em Estudos Urbanos e Regionais, e-mail: felipefernandesdearaujo@gmail.com
} 
space. Spatial innovation and its dissemination (convention), promoted by urban entrepreneurs in order to maximize profits, generates, as a rule, a certain homogenization of residential space; in this case, through the promotion of 'Condomínios-clubes.' Based on authors such as David Harvey and Pedro Abramo to analyze the theoretical background, it is possible to understand the relationship between urban spatial form and capitalist development. In addition to a literature review, the methodology of this study also included open interviews with real estate managers in order to consider the relation between the built environment (housing stock) and the hegemonic discourse that seems to guide the residential market in the city. The results clearly show that this discourse tends towards a common objective; there is a convergence in the thinking and practice of real estate agents regarding the location and characteristics of each sort of real estate development. This has caused a sociospatial homogenization of certain neighborhoods at the expense of the rest of the city.

Keywords: Spatial innovation. Urban convention. Spatial segmentation. 'Condomínios-clube'. Production of space.

\section{Introdução: Ajustes teórico-metodológicos}

O aumento considerável no número de lançamentos imobiliários e o crescimento na escala dos empreendimentos em Natal/RN são claros sinais da dinâmica imobiliária na cidade e de sua importância para a economia política local. A Zona Sul da cidade tem recebido significativos investimentos públicos e privados, nos últimos anos, muitos dos quais atrelados ao desenvolvimento da atividade turística, implicando na construção de importante infraestrutura urbana, que propiciou o aquecimento do mercado imobiliário. Ocupada, em grande parte, por conjuntos habitacionais construídos pelo Banco Nacional da Habitação (BNH), essa parte da cidade se transforma com o processo de verticalização, a partir da década de 1990.

Mais recentemente, no entanto, pode-se observar a chegada de uma nova tipologia que vem se disseminando nessa parte da cidade, ao longo de importantes eixos viários: são os chamados condomínios-clube. A tipologia condomínio-clube, que surgiu no Brasil a partir dos grandes centros urbanos, caracteriza-se pela presença de uma grande e variada infraestrutura de lazer construída nas áreas comuns dos empreendimentos. Chegou a Natal recentemente, tornando-se uma "febre" nos lançamentos imobiliários locais. A necessidade de grandes terrenos justifica sua localização na área de expansão em direção ao município de Parnamirim, uma vez que a cidade de Natal apresenta uma área relativamente pequena e com poucos terrenos disponíveis e caros.
O crescimento urbano de Natal, nos últimos anos, está, assim, também associado à expansão em direção aos municípios metropolitanos. Esse crescimento pode ser visto pelo movimento físico, de expansão da malha urbana, e pelo movimento socioeconômico, que integra um conjunto de atividades, tais como habitação, serviços, consumo, indústria. Nesse contexto, Parnamirim - que faz limite com a Zona Sul de Natal - é o município em que tal crescimento se dá de maneira mais forte e visível na paisagem urbana, refletindo significativas transformações espaciais. Dentre tais transformações, merece destaque o expressivo crescimento da área, via mercado imobiliário, modificando a dinâmica espacial da cidade com a edificação de novas moradias e de outras edificações para abrigar as novas atividades comerciais e de serviços, além da necessária infraestrutura.

Essa nova dinâmica urbana, em Natal, despertou o interesse em compreender, de maneira mais aprofundada, as determinações e condicionantes que orientam o surgimento e a disseminação dos empreendimentos do tipo "clube" nessa parcela da cidade. Por que os empresários urbanos adotaram esse novo conceito de moradia em Natal? Por que se localizam, predominantemente, nessa parte da cidade e não em outra? Qual sua relação com a segmentação espacial existente na cidade?

A produção do espaço é um processo que envolve diversos agentes, que estão em constante conflito, na busca de seus interesses. Esse trabalho privilegia a forma como um agente produtor do espaço atua no mercado residencial: os empresários urbanos. Não se descarta a importância dos demais agentes, 
como o Estado, as instituições financeiras ou os trabalhadores e outros que representam a demanda em busca de habitação, porém o que se quer enfatizar é a participação dos empresários urbanos na configuração residencial, em uma escala de tempo muito rápida. Deve-se deixar claro que este trabalho discute as causas ou condições para o surgimento desse fenômeno em Natal. Os efeitos desse processo, em termos de impactos ambientais, sociais e na própria gestão urbana, podem ser discutidos em trabalhos futuros.

Com o objetivo de compreender a chegada da nova tipologia do condomínio-clube, inserido na lógica de produção do espaço dos empresários urbanos, o procedimento metodológico adotado foi a realização de entrevistas abertas, semiestruturadas, junto aos agentes do mercado imobiliário, para abranger a relação entre a materialidade espacial construída (estoques habitacionais) e o discurso hegemônico que orienta a configuração residencial na cidade.

0 primeiro entrevistado foi um advogado especialista no setor imobiliário, que possui uma visão abrangente sobre a atuação dos empresários urbanos na estrutura residencial de Natal, e possibilitou o contato com representantes de quatro imobiliárias que comercializam condomínios-clube em Natal. São elas: Abreu Imóveis, NL Imóveis, ECM Imóveis e Procuradoria de Imóveis. Com relação aos critérios para a escolha dos entrevistados, optou-se por entrevistar representantes de construtoras ou incorporadoras que possuem empreendimentos do tipo condomínio-clube localizados na área de estudo do presente trabalho. Foram entrevistados os representantes das seguintes empresas: Cyrela Plano \& Plano, Moura Dubeux, Diagonal/Rossi, Estrutural e Ecocil. No total, foram realizadas dez entrevistas, que foram gravadas e transcritas.

Com relação aos dados quantitativos, a Prefeitura de Parnamirim disponibilizou os dados de licenciamento dos anos de 2008, 2009 e 2010, que foram importantes para comprovar o grande crescimento de empreendimentos no município, inclusive em relação ao porte das construções. Os dados da Prefeitura de Natal se referem ao ano de 2010. Utiliza-se como início do recorte temporal o ano de 2009 porque é justamente quando se iniciam os licenciamentos dos primeiros condomínios-clube na área de pesquisa. Trata-se, portanto, de um fenômeno bastante novo.
A área de estudo compreende parte da Zona Sul de Natal em direção ao município de Parnamirim, alcançando os bairros de Nova Parnamirim e Emaús. A expansão da mancha urbana propiciou a criação da Região Metropolitana de Natal em 1997, embora não tenha se estabelecido um processo claro de conurbação, e sim "uma mancha de 'transbordamento' e fragmentação do espaço metropolitano, onde problemas de ordem socioespacial são frequentes e persistentes" (Silva, 2010, p. 268-269).

Teoricamente, o conceito de destruição criativa, resgatado por David Harvey, permite compreender o movimento de transformação incessante do espaço construído. Assim, ao discutir a ação dos empresários urbanos especificamente no mercado residencial, Pedro Abramo utiliza tal conceito para tratar das inovações espaciais. Essa ponte teórica permite estabelecer um nível de análise mais local. É o que veremos a seguir.

\section{Destruição criativa e inovação espacial: As transformações no espaço construído}

A lógica espacial da acumulação capitalista é um tema discutido por alguns autores que buscam compreender a relação dialética entre o desenvolvimento capitalista e a forma espacial urbana. Nesse sentido, a urbanização é vista como uma manifestação espacial do processo de acumulação de capital. Podem-se destacar, nesse âmbito, os estudos de David Harvey e Neil Smith, porém foi o próprio Lefebvre (2008) quem chamou a atenção para as contradições e especificidades do espaço construído, ou do imobiliário, na sociedade capitalista. 0 setor imobiliário é visto como um setor secundário, um circuito paralelo ao da produção industrial. Tal setor tem o papel de absorver os choques das crises produtivas: "Em caso de depressão, para ele afluem os capitais" (Lefebvre, 2008, p. 144). Lefebvre (2008, p. 144) chega mesmo a afirmar que há situações em que "o segundo circuito suplanta o principal. De contigente, torna-se essencial".

Com base em Lefebvre, Harvey (1989) propõe uma distinção entre o circuito primário, secundário e terciário da economia. 0 circuito primário é o lócus da produção de mais-valia e do consumo, assim como da reprodução da força de trabalho; o circuito secundário envolve o investimento de capital especificamente em capital fixo e no setor imobiliário; 
e o terciário é a esfera do investimento na ciência, educação, tecnologia e em gastos sociais (Harvey, 1989; Valença, 2008). Para o presente trabalho, destaca-se o circuito secundário, com o intuito de compreender como as transformações no espaço construído são importantes para a reprodução de capital, uma vez que, para promover a reprodução ampliada do capital, necessitam-se imobilizar no espaço grandes quantidades de capital fixo.

Para Harvey (2005), as contradições inerentes ao sistema capitalista resultam em crises de sobreacumulação, oriundas da competição entre os capitalistas. 0 excesso de capital se dá como excedente de mercadorias, de moeda, de força de trabalho. A maneira encontrada para solucionar a crise é o ajuste espacial. Além de tecnologicamente dinâmico, o modo de produção capitalista é intrinsecamente expansionista. A necessidade de acumulação de capital leva a uma franca expansão geográfica da sociedade capitalista, conduzida pelo capital produtivo. Isso exige um contínuo investimento de capital na criação de um ambiente construído para a produção. Estradas, ferrovias, fábricas, oficinas, armazéns, portos, usinas de energia. Estas e outras infraestruturas são as formas geograficamente imobilizadas de capital fixo, tão fundamentais ao progresso da acumulação (Smith, 1984; Valença, 2008). Como o capitalismo busca incessantemente reduzir os custos de realização e de circulação acelerando o giro de rotação do capital, o processo de acumulação reforça seu caráter geograficamente expansível, a partir da redução dos custos de transporte e de comunicação, o que só é possível pela superação das barreiras espaciais num processo de "aniquilamento do espaço pelo tempo", como descreveu Marx (Harvey, 1989).

A crise no circuito primário poderia ser evitada, transferindo-se investimentos de capital para os setores secundário e terciário. 0 setor secundário, e em particular o meio ambiente construído, tende a ser subcapitalizado, por causa da larga escala de tais investimentos, de seu longo período de movimentação e de sua tendência a serem coletivamente consumidos. Essa transferência de capital para o meio ambiente construído é facilitada por certo número de instituições, particularmente o sistema de crédito e o Estado (Harvey, 1989; Smith, 1984; Valença, 2008).

O investimento de capital no ambiente construído está em sincronia com o ritmo cíclico mais geral de acumulação do capital. 0 ritmo histórico do investimento no ambiente construído forja padrões geográficos específicos que, por sua vez, influenciam fortemente o programa de acumulação do capital (Smith, 1984). A obsolescência de velhas tecnologias e o surgimento de novas, tão vital para o capitalismo, é simultaneamente a transformação de velhas estruturas espaciais em novas (Smith, 1984).

É justamente a busca por novas formas espaciais que abre caminho para a discussão sobre o processo de destruição criativa. De acordo com Schumpeter (1984), a destruição criativa é o fato essencial do capitalismo. 0 capitalismo é intrinsecamente dinâmico e tal processo baseia-se nas inovações criadas pelos empreendedores, no âmbito da concorrência entre as empresas. Esse processo pode estar atrelado à criação de um novo bem, de um novo método de produção, à abertura de um novo mercado, à descoberta de uma nova fonte de matéria-prima ou à introdução de uma nova organização econômica, como o estabelecimento de uma situação de monopólio, por exemplo. Schumpeter (1984) destaca a intuição dos empreendedores como fundamental para o processo de inovação, revolucionando incessantemente a estrutura produtiva.

A destruição criativa se manifesta na esfera do consumo, nas relações sociais e na paisagem das cidades. 0 processo de reprodução material e social torna dinâmica a própria constituição do capital, que conecta o mundo e garante sua sobrevivência por meio da destruição e reconstrução acelerada dos processos de produção e das relações interligadas a ele. Fato que compreende também a dimensão espacial, visto que o capital necessita constantemente expandir seus mercados tanto em investimentos quanto em consumo. De acordo com Harvey (1996), a acumulação de capital e a expansão territorial constituem a lógica da destruição criativa.

0 efeito da inovação contínua é, no entanto, desvalorizar, senão destruir, investimentos e habilidades de trabalho passados. A destruição criativa está embutida na própria circulação do capital. A inovação exacerba a instabilidade e a insegurança, tornando-se no final a principal força que leva o capitalismo a periódicos paroxismos de crise (Harvey, 1996, p. 102).

As crises desenvolvidas no sistema geral da produção capitalista tem-se manifestado cada vez mais 
diretamente na geografia do capitalismo. A diferenciação do espaço é resultado da necessidade inerente ao capital de imobilizar-se na paisagem. Obviamente, todas essas transformações implicam em mudanças na dinâmica espacial da cidade, promovendo diferenciações espaciais que se expressam em valorização/ desvalorização imobiliária. 0 desenvolvimento desigual é a desigualdade social estampada na paisagem geográfica e é simultaneamente a exploração daquela desigualdade geográfica para certos fins sociais determinados (Smith, 1984).

A destruição criativa se encarrega de criar novas paisagens geográficas que atendam aos interesses dos agentes produtores do espaço. Valença (2006, p. 186) explica que "tanto a cidade é importante para a acumulação de capital em geral - produção e consumo de mercadorias e reprodução da força de trabalho - como a produção do espaço urbano é, ela própria, parte nada desprezível dessa acumulação". Em outras palavras, a produção do espaço é fundamental para a sobrevivência do capitalismo, que impõe a lógica de reprodução das relações sociais de produção, seja em nível global ou local.

Abramo (1995) chama a atenção para o fato de que a relação entre urbanização e acumulação capitalista pode ser compreendida por meio da utilização de conceitos intermediários da Escola de Regulação Francesa, uma vez que abre novas possibilidades de análise entre o econômico, o urbano e o imobiliário. De maneira geral, Abramo (1995) destaca que a funcionalidade da estrutura urbana em relação ao processo de valorização de capital muda ao longo do tempo e do espaço, de acordo com o modo de regulação e o regime de acumulação dominante. Como consequência, temse "uma modificação nas formas de produção das materialidades urbanas construídas e nos critérios locacionais que direcionam as decisões dos agentes sociais" (Abramo, 1995, p. 550).

De acordo com Carlos (1999), o processo de reprodução do espaço se submete cada vez mais ao jogo do mercado imobiliário - na medida em que há novas estratégias para a acumulação por meio dos empreendedores imobiliários - e às políticas estratégicas do Estado, que tende a criar o espaço da dominação e do controle.

Essa breve discussão serviu para explicitar por que as transformações na dinâmica espacial das cidades são importantes para a acumulação capitalista. Aproxima-se, portanto, do objetivo a seguir, que é compreender as estratégias de atuação dos empresários urbanos na configuração residencial. Para tanto, será realizada uma leitura do mercado residencial com base nas ideias de Pedro Abramo.

O capitalista-empresário é o agente cuja decisão de produzir desencadeia os demais atos de despesa monetária. Abramo (2007a) utiliza-se do conceito de destruição criativa de Schumpeter (1984) para analisar a prática da inovação espacial no espaço urbano. Nesse sentido, Abramo (2007a) enxerga na prática dos empresários urbanos uma semelhança com o empreendedor schumpeteriano: a busca ininterrupta por inovações-diferenciações. Diferentemente do âmbito da macroeconomia, no caso do mercado residencial, os empresários urbanos promovem a destruição de uma paisagem anterior e a modificam, na busca por lucros excepcionais, por meio da inovação espacial. Tais práticas produzem mudanças tanto nas características do bem residencial, quanto na configuração das externalidades de vizinhança. A permanente destruição criativa implica em uma ordem urbana caleidoscópica, instável, incerta.

Ao propor modificações no bem residencial, os empresários urbanos induzem mudanças nas preferências dos trabalhadores, "uma espécie de efeito de moda graças ao qual os imóveis, quando envelhecem, perdem a capacidade concorrencial" (Abramo, 2007a, p. 81). Isso significa dizer que os estoques mais antigos sofrem uma depreciação "fictícia" em relação aos mais recentes. Na verdade, a depreciação fictícia que os empresários almejam produz a destruição criativa de todos os estoques residenciais de maneira indireta. Em geral, essa depreciação preserva fisicamente o estoque residencial e, ao mesmo tempo, propicia a modificação de sua externalidade de vizinhança.

Apesar da importância da estratégia da inovação, Abramo (2007a) destaca que não se deve esquecer a dimensão espacial da habitação, uma vez que está diretamente atrelada à questão da localização. Devido ao fato de ser um bem imóvel e de alta durabilidade, a diferenciação do produto se realiza por meio de deslocamentos espaciais da demanda residencial. Quando os trabalhadores decidem comprar um bem residencial, raciocinam mais por uma lógica de localização do que pelo produto em si. Como o produto é definido pela busca de externalidades de vizinhança, a inovação espacial só poderá ser 
definida com base em uma nova oferta de localização que possa atrair tipos de famílias que, a princípio, tenderiam a se transferir para outro local. Assim sendo, "as diferenciações do produto habitação serão utilizadas mais frequentemente para propor novas localizações que possam reunir famílias de um tipo particular e produzir uma certa externalidade de vizinhança em outro local" (Abramo, 2007a, p. 84).

Ao gerar uma diferenciação do produto-habitação e impor uma margem de ganho, gera-se também uma valorização da localização convencionada em relação à estrutura residencial anterior (depreciação "fictícia" dos estoques passados), levando as famílias a acreditarem que a crença na convenção se confirmou. Tal efeito de valorização é discutido por Abramo (2007a, p. 157-158) como responsável pela "manutenção do caráter segmentado das proposições de localização residencial em termos econômicoespaciais", uma vez que impede a entrada de famílias com status social mais baixo do que a convenção propõe. Nesse sentido, a valorização reforça as condições de emergência de uma externalidade de vizinhança correspondente a um tipo homogêneo de famílias.

Essa segmentação responde a duas ordens de motivos diferentes. Do ponto de vista da oferta, isto é, dos empresários urbanos, a segmentação da demanda permite uma redução dos riscos e das incertezas dos empreendimentos imobiliários. Do ponto de vista da demanda, a segmentação do mercado imobiliário garante uma relativa homogeneidade socioespacial do seu entorno residencial. Em outras palavras, uma estrutura de oferta residencial segmentada em termos socioeconômicos promove uma estrutura espacial segmentada em termos socioespaciais (Abramo, 2007b).

Após essa discussão teórica, faz-se necessário, a seguir, compreender mais de perto a realidade espacial da cidade de Natal, por meio da relação entre as transformações espaciais, a ação dos empresários urbanos e a segmentação da configuração residencial.

\section{As transformações espaciais na Zona Sul de Natal, RN}

Clementino (1995) divide o processo de produção do espaço urbano de Natal em quatro períodos: a) antes da Segunda Guerra Mundial, o processo de concentração de pessoas e atividades é lento; b) durante a Segunda Guerra Mundial, intensifica-se o fluxo migratório e crescem as atividades comerciais e os serviços; c) o período entre 1950 e 1960 caracteriza-se pela especulação imobiliária através de loteamentos, pelo surgimento dos primeiros programas habitacionais e pela infraestrutura criada com recursos governamentais; d) somente a partir de 1970 tem-se a transição para a sociedade urbana, com a dinamização da construção civil, o aumento da especulação imobiliária e da valorização da terra urbana, a construção de grandes conjuntos habitacionais na periferia, a verticalização do centro e o início da atividade turística.

Após o impacto da Segunda Grande Guerra, inicia-se uma nova fase para a urbanização de Natal, associada ao crescimento das atividades já existentes e ao aumento do contingente populacional, que foram consequências das políticas de desenvolvimento de caráter urbano-industrial realizadas em nível nacional, que refletiram em Natal (Costa, 2000).

Ferreira (1996) explicita a importância dos loteamentos privados do solo para a expansão da cidade, consolidando a rede viária e delineando sua configuração até os dias de hoje. 0 surgimento desses parcelamentos está atrelado ao crescimento populacional e à criação de infraestrutura viária no período da Segunda Guerra Mundial. Tais loteamentos se proliferaram orientados principalmente pelo novo eixo viário entre Natal e Parnamirim.

Em razão da especulação, a cidade vê o surgimento dos primeiros loteamentos, indicando um vetor de expansão do mercado de terras rumo à Zona Sul, que margeava a Parnamirim Road em um traçado que abria diversas artérias paralelas à "pista" (Furtado, 2007, p. 110).

De acordo com Silva (2010), os empresários da construção civil, proprietários fundiários e incorporadores se apropriaram das rendas fundiárias por meio da transformação do solo rural em urbano. Na década de 1980, toda a área do município de Natal já era urbana, com o solo da cidade parcelado. Correa (1995) mostra que, no geral, a propriedade fundiária da periferia urbana está diretamente submetida ao processo de transformação do espaço rural em urbano, valorizando a área e aumentando o seu preço.

A política habitacional desencadeada a partir da criação do BNH, em 1964, teve um papel decisivo 
para a urbanização das cidades brasileiras. Em Natal, a construção dos conjuntos foi promovida pela Companhia Habitacional Popular (Cohab) e pelo Instituto de Orientação às Cooperativas Habitacionais (Inocoop), que contou com recursos oriundos do Sistema Financeiro da Habitação (SFH). A localização periférica dos conjuntos habitacionais foi determinante para a formação de vazios urbanos e o avanço da especulação imobiliária, com a existência de muitos lotes ociosos na cidade, à espera da valorização que advém da provisão de infraestruturas urbanas e ofertas de serviços.

É importante fazer uma breve distinção entre bairros de elite, bairros de status e bairros de estigma em Natal. Tal diferenciação espacial pode ser considerada levando em conta as práticas espaciais responsáveis pela materialização do espaço construído, bem como a simbologia e o imaginário que os diferentes bairros apresentam para a população em geral, muitas vezes construídos pelos empresários urbanos, produzindo representações do espaço. A Figura 1 expressa a localização da população de Natal de acordo com a renda e reflete a dinâmica espacial da cidade.

No primeiro caso, levando em consideração o poder aquisitivo dos moradores, o padrão arquitetônico dos empreendimentos e a infraestrutura urbana construída, os bairros de Tirol e Petrópolis (Zona Leste) podem ser tradicionalmente considerados de elite, por abrigarem historicamente a população mais rica da cidade, constituindo-se na área de maior valorização imobiliária de Natal. Pode-se perceber, no discurso dos agentes entrevistados, que tais bairros são sinônimos de qualidade de vida: "A população de alto padrão já elegeu alguns bairros como qualidade. Ela quer morar em Tirol, Petrópolis, Areia Preta (informação verbal do representante da NL Imóveis).

Com relação aos bairros de status, localizam-se na Zona Sul da cidade, historicamente ocupada por conjuntos habitacionais de classe média, em uma área em que o Estado realizou grandes investimentos, principalmente para promover a atração turística. Segundo Furtado (2007, p. 144), “[...] as intervenções públicas são direcionadas para além do 'olhar' do turista e beneficiam também os bairros de status [...]". Nesse sentido, embora tais bairros não estejam estruturados para o turismo, é possível observar que há um processo de embelezamento da cidade e uma procura por tornar seu espaço harmonioso, principalmente no que se refere àqueles onde transitam os turistas e as elites locais. Ao analisar a relação entre o processo de mudanças estruturais e embelezamento urbano e a consolidação de bairros privilegiados, a autora defende que os bairros da Zona Sul estão inseridos na "onda do turismo".

Os conjuntos habitacionais localizados na Zona Sul abrigam uma população com rendimentos significativos e bom padrão de vida, constituindose uma classe média formada por funcionários públicos, militares e profissionais liberais (Medeiros, $2007)^{2}$. Com base em Abramo (2007a), compreendese que a externalidade de vizinhança oriunda de tal homogeneidade social foi fundamental para a posterior valorização das moradias nos conjuntos habitacionais da Zona Sul. De maneira geral, entre os conjuntos habitacionais produzidos na Zona Sul e próximo a eles, têm se consolidado os condomínios fechados verticais, enquanto nos conjuntos habitacionais produzidos na Zona Norte observa-se a proliferação dos loteamentos e ocupações irregulares.

A construção de tais conjuntos possibilitou uma ocupação mais intensa da Zona Sul, representando o primeiro ciclo de vida dos seus estoques residenciais. Se, de um lado, observa-se uma nova forma de "morar" nos edifícios que se erguem e em que se abrigam as classes de maior renda, de outro, expandem-se os bairros para a classe média (Furtado, 2007). De acordo com Furtado (2007), as moradias em conjuntos habitacionais só começaram a perder valor quando a população local incorporou a "cultura" do apartamento. Em outras palavras, o surgimento de uma inovação espacial provocou a depreciação "fictícia" dos estoques nos conjuntos habitacionais e a consolidação de uma nova convenção urbana.

Portanto, o espaço da Zona Sul de Natal continua sendo produzido para atender, em sua maioria, as demandas da classe média da cidade. Nesse sentido, por um lado, um empreendimento imobiliário em tal localização torna-se mais atrativo para os empresários urbanos pelo fato de encontrar uma demanda capaz de pagar o acesso à moradia. Por outro lado, possibilita externalidades de vizinhança

\footnotetext{
2 A análise que perpassa o texto utiliza a classificação da população de acordo com a renda com base no Instituto Brasileiro de Geografia e Estatística (IBGE, 2010) em: classe A, aqueles que ganham acima de 15 salários-mínimos; classe B, entre 5 e $15 \mathrm{sm}$; classe $C$ entre 3 e $5 \mathrm{sm}$; classe D entre 1 e $3 \mathrm{sm}$ e a classe E até $1 \mathrm{sm}$.
} 
que são despertadas por meio das representações inerentes aos bairros de status.

Por fim, os bairros de estigma são aqueles ocupados, em sua maioria, pela população de baixa renda, com infraestrutura urbana deficiente, que são vistos pelo "outro" como locus da violência e criminalidade. Em Natal, os exemplos mais próximos de tal perspectiva se encontram nos bairros das zonas Oeste e Norte da cidade. Com relação ao mercado imobiliário, tais áreas não são atrativas porque a

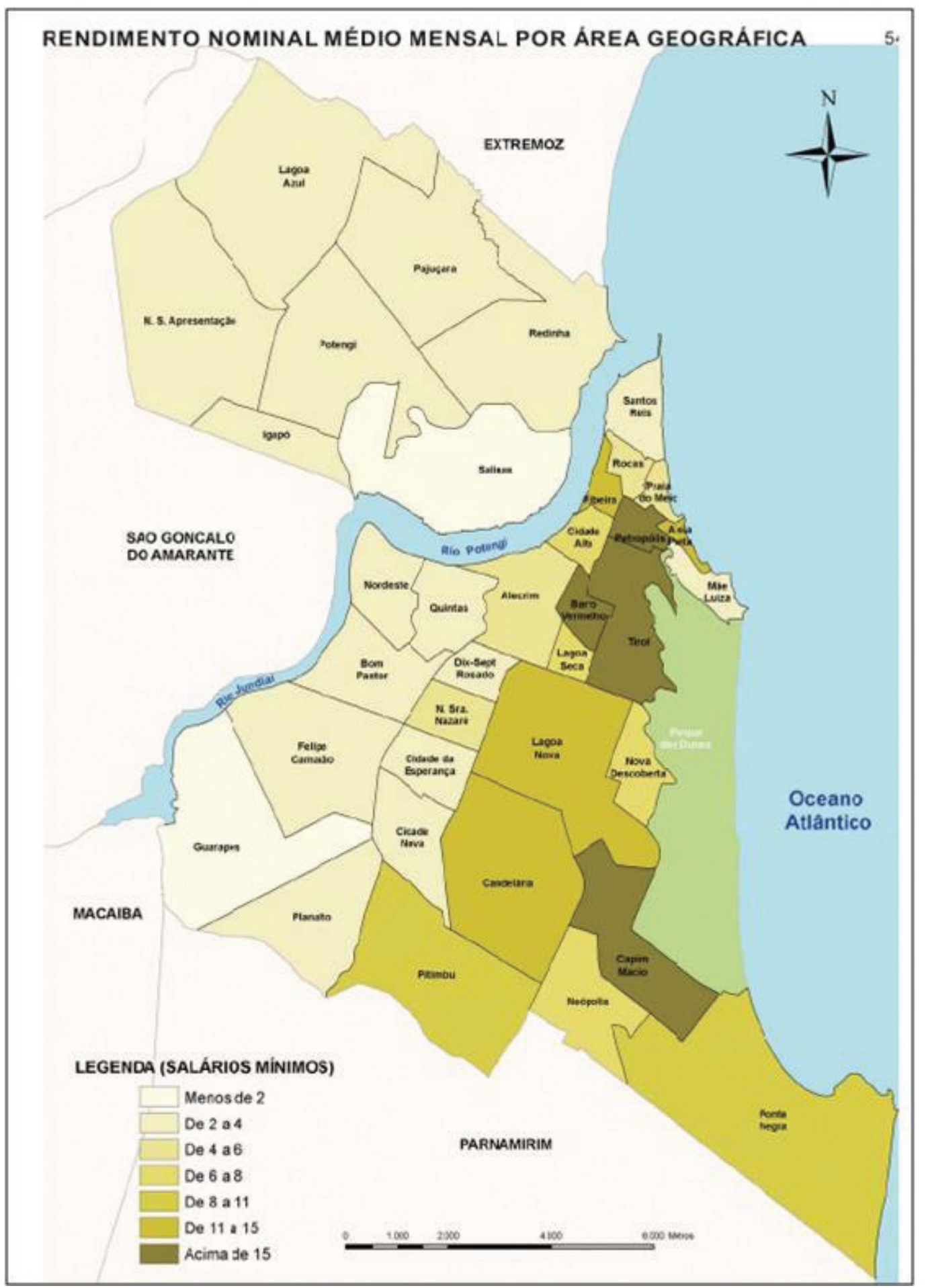

Figura 1 - Localizacãa da população de Natal de acordo com a renda Fonte: Natal (2010). 
população não representa demanda efetiva, porém percebe-se no discurso dos empresários urbanos a importância das externalidades de vizinhança na dinâmica espacial quando um dos entrevistados revela que "há uma rejeição natural da cidade de Natal, de que Zona Norte é pobre, Zona Norte é longe" (informação verbal do representante da Cyrela).

Feita essa breve análise espacial da estrutura urbana da cidade, é notória, pois, a segmentação residencial na cidade. É possível perceber claramente a maneira como os empresários urbanos "adequam" o padrão arquitetônico dos empreendimentos de acordo com a localização em que vão ser construídos.

Na década de 1990, o índice de urbanização do município de Natal se intensifica ainda mais. Registra-se nesse período o incremento na ocupação da faixa litorânea, ao norte e ao sul de Natal, como consequência do desenvolvimento do turismo. Acentua-se a tendência de crescimento de Natal para além dos seus limites, constituindo a base de sua Região Metropolitana. 0 processo de verticalização da cidade se torna ainda mais visível, tanto nos bairros centrais quanto nos bairros da Zona Sul (Nobre, 2001).

Para Costa (2000), o período correspondente à década de 1990 caracterizou-se por ser o de maior crescimento vertical na cidade até então, concentrando 367 construções ou $67 \%$ de todas as construções verticais realizadas em Natal, sendo 92\% de prédios residenciais. $\mathrm{O}$ autor afirma que o aumento da demanda por habitações em edifícios verticais em Natal está relacionado à criminalidade urbana e ao prestígio social que esse tipo de residência desfruta entre as camadas de maior poder aquisitivo. De acordo com dados da Prefeitura de Natal, no ano de 2010, foram licenciados 7.282 imóveis de usos comercial, residencial e misto na Zona Sul de Natal. Desse total, 5.872 são de imóveis residenciais. 0 que chama a atenção é o fato de que 5.782 desses imóveis residenciais são multifamiliares, isto é, apartamentos, o que representa $98,4 \%$ do total. Fica clara a disseminação da verticalização nessa parte da cidade. 0 total da área dos terrenos licenciados chega a 103,7 hectares. Diversas implicações podem ser observadas devido ao incremento da porcentagem de apartamentos nessa porção da cidade, principalmente no que diz respeito a impactos ambientais, aumento dos congestionamentos no trânsito, mudança da paisagem natural e na própria gestão urbana, devido ao maior adensamento habitacional e consequente aumento na demanda por serviços públicos.

Tal processo culminou com o transbordamento do mercado imobiliário de Natal para o município vizinho de Parnamirim, aproveitando-se de uma legislação urbanística menos restritiva, do solo urbano mais barato e da maior disponibilidade de glebas grandes. No início da década de 1990, a maioria dos lançamentos imobiliários se localizava na Zona Sul, quando a cidade começava a se expandir em direção ao município vizinho, Parnamirim (Nobre, 2001). De acordo com Silva (2010, p. 245), formou-se um novo "eixo imobiliário às margens da Av. Ayrton Senna e Av. Maria Lacerda, integrando com a Rota do Sol, via de acesso às praias do litoral sul" (Silva, 2010, p. 245).

Marta Turra (2003) estuda outro momento importante para a expansão da Grande Natal: os financiamentos habitacionais da Caixa Econômica Federal, no período de 1995 a 2002. Dois bairros foram os mais impactados com a corrida imobiliária para além dos limites administrativos do município de Natal: Nova Parnamirim e Emaús. Turra (2003, p. 94) desvenda um dos motivos para tal expansão: "Em relação às duas áreas (Nova Parnamirim e Emaús) cabe acrescentar que as mesmas não são cobertas pelo Plano Diretor de Natal, o que permite inferir que este fato pode ser considerado um atrativo extra para os investimentos em moradia na região".

Além disso, a ligação entre Natal e Parnamirim através da BR-101 e da Avenida Ayrton Senna, bem como a ligação dessas duas vias entre si pelas avenidas Abel Cabral e Maria Lacerda Montenegro, definiu um "novo quadrilátero dos investimentos e negócios imobiliários na Grande Natal" (Turra, 2003, p. 107) e propiciou a instalação de serviços especializados, como de saúde, gêneros alimentícios, material de construção, educação. Pelo fato dos bairros de Nova Parnamirim e Emaús serem limítrofes com o município de Natal e cortados por tais eixos viários, os investimentos imobiliários foram mais intensos nesses bairros. "Em toda essa extensão, predomina a construção de edifícios residenciais, representando uma maior tendência de urbanização vertical quanto maior for a proximidade da divisa entre os municípios de Natal e Parnamirim" (Turra, 2003, p. 112).

Com base nos dados de licenciamentos da Prefeitura de Parnamirim (Parnamirim, 2010), observa-se que houve um aumento significativo 
no número de unidades licenciadas entre 2008 e 2010, o que indica o aquecimento do setor imobiliário no município. Além disso, em 2010, o total de unidades multifamiliares (apartamentos) representou aproximadamente 95\% do total de unidades licenciadas no ano, conforme pode ser visto na Tabela 1.

De acordo com o IBGE (2010), no ano 2000 a cidade de Natal possuía 14 mil unidades de apartamento, o que representava $7 \%$ do total de habitações. No último censo, esse número passou para 28 mil. Os apartamentos agora representam $12 \%$ do total. A vizinha Parnamirim acompanha o crescimento da capital. No ano 2000, o município possuía 3 mil unidades de apartamento. 0 último censo revelou que esse número subiu para 7 mil. É importante observar também que os lançamentos mais recentes em Parnamirim caracterizam-se por serem de maior porte, fazendo uso de grandes terrenos (Tabela 2). De acordo com os dados da Prefeitura de Parnamirim (2010), com base nos alvarás emitidos entre 2008 e 2010, pode-se constatar o aumento significativo na área licenciada da cidade, o que expressa o aquecimento do seu mercado imobiliário. Esse crescimento a partir de 2009 está diretamente ligado aos licenciamentos

Tabela 1 - Unidades habitacionais licenciadas entre 2008 e 2010 em Parnamirim

\begin{tabular}{ccc}
\hline ANO & $\begin{array}{c}\text { UNIDADES HABITACIO- } \\
\text { NAIS LICENCIADAS }\end{array}$ & TOTAL DE APARTAMENTOS \\
\hline 2008 & 904 & 337 \\
2009 & 5.354 & 4.474 \\
2010 & 12.445 & 11.799 \\
\hline
\end{tabular}

Fonte: Parnamirim (2010).

Tabela 2 - Área total dos terrenos licenciados entre 2008 e 2010 em Parnamirim

\begin{tabular}{cc}
\hline ANO & $\begin{array}{c}\text { ÁREA TOTAL DOS TERRENOS } \\
\text { LICENCIADOS (ha) }\end{array}$ \\
\hline 2008 & 14,8 \\
2009 & 41,3 \\
2010 & 108,9 \\
\hline
\end{tabular}

Fonte: Parnamirim (2010). dos condomínios-clube. A seguir, será aprofundada a discussão sobre essa nova tipologia.

\section{A nova estratégia dos empresários urbanos na configuração residencial: Os condomínios- clube e sua localização na cidade}

A definição de condomínio-clube está associada aos empreendimentos verticais que destinam grandes áreas do terreno para a instalação de opções de lazer, privilegiando as áreas comuns externas, o que implica na necessidade de terrenos de grande extensão (Sampaio, 2009; Campos, 2007). Essa tipologia originou-se na década de 1970 nos empreendimentos construídos na Barra da Tijuca, no Rio de Janeiro, e tem sua imagem associada à possibilidade de ter acesso ao lazer sem a necessidade de enfrentar a violência e os perigos da cidade (Sampaio, 2009).

Para Nobre (2001), na década de 1990, em Natal, há uma inovação no que se refere às campanhas publicitárias, introduzindo um elemento capaz de gerar lucros excepcionais à produção imobiliária: o acesso a uma bela vista. A paisagem torna-se um ativo para os empresários urbanos atraírem novos consumidores:

[...] as campanhas publicitárias realizadas antes da construção dos edifícios são mais elaboradas, uma vez que, não estando pronto o produto, a necessidade de despertar o interesse do comprador torna-se mais intensa. Entende-se que nesse contexto as menções à paisagem ocorram com maior frequência, tendo em vista o poder de sedução nela implícito (Nobre, 2001, p. 98).

No caso dos condomínios-clube, a área de lazer cada vez mais assume posição de destaque nos informes publicitários do mercado imobiliário residencial. Os espaços comuns que são entregues "equipados e decorados" abrangem diversos itens de lazer, como sala de ginástica, complexo de piscinas, quadras poliesportivas, lan house, brinquedoteca, salão de jogos, espaço gourmet, playground, salão de festas, pista de cooper etc. A própria quantidade de itens de lazer passa a ser alvo de disputa entre as empresas concorrentes. A Tabela 3 ilustra alguns empreendimentos localizados na área de estudo e a 
maneira pelas quais o marketing utiliza os itens de lazer para atrair os consumidores.

A publicidade usada para a divulgação dos empreendimentos imobiliários, adotando os mais variados recursos, mais que divulgar a oportunidade

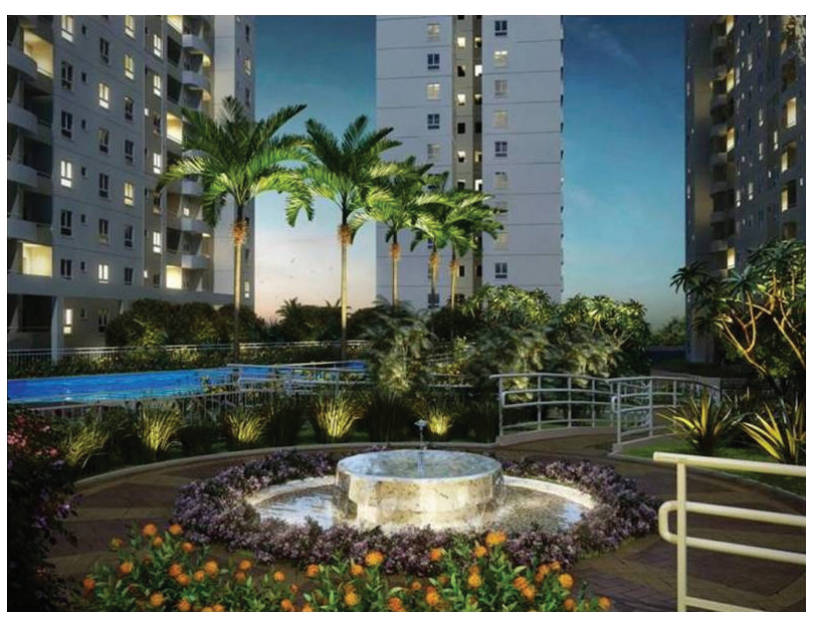

Figura 2 - Projeto da área externa do Vita Residencial Clube Fonte: Panfleto publicitário.

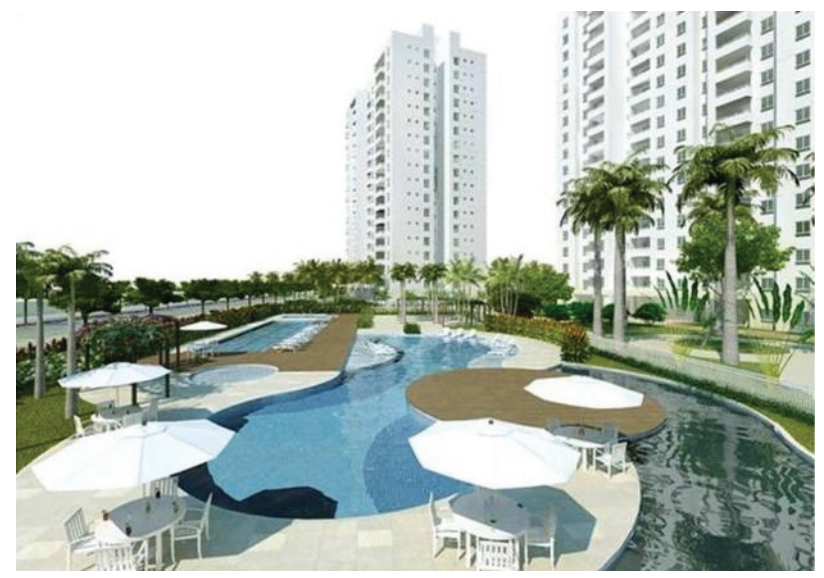

Figura 3 - Projeto da área externa do L'ácqua Condominium Club Fonte: Panfleto publicitário. de negócios, se volta a vender o paraíso, como ilustram as Figuras 2 e 3. A identificação do públicoalvo e da faixa de renda, selecionada para a aquisição de cada produto, fica claramente evidenciada nos recursos, no apelo ao imaginário e na linguagem explorados pela publicidade. "A dinâmica do mundo atual, o estresse generalizado, a falta de tempo, de paciência e tantas outras faltas levam à busca desenfreada por uma compensação. Todos desejam e necessitam de momentos de lazer, de paz, de segurança e de felicidade" (Oliveira et al., 2010).

Enfim, compreende-se que as estratégias dos empresários urbanos se utilizam da recriação constante de um ideal de morar, introduzindo novos produtos que satisfaçam as expectativas dos consumidores e criando novas necessidades, ou seja, por meio do constante processo de inovação espacial. As novas necessidades fazem parte das estratégias do discurso hegemônico imposto pelos empresários urbanos, realizado através dos anúncios imobiliários, que buscam seduzir o público alvo e criar no imaginário uma relação de pertencimento de um "novo estilo de vida" (Guerra, 2013). 0 condomínio-clube agrega todas essas representações, embora exacerbe os itens de lazer como principal característica. Esse novo momento representa uma diferenciação com relação aos empreendimentos anteriores, que passam por uma "depreciação fictícia", uma vez que a população passa a preferir aqueles empreendimentos que adotam o "clube" como padrão. Nesse sentido, os condomínios-clube estão na moda.

Em Natal, a partir dos anos 2000, a disseminação de tal tipologia está associada à vinda de grandes incorporadoras nacionais, tais como a Cyrela (de São Paulo), a Rossi (de São Paulo) - em parceria com a Diagonal (de Fortaleza) -, a Moura Dubeux (de

Tabela 3 - A utilização do lazer no marketing imobiliário

\begin{tabular}{ll}
\hline \multicolumn{1}{c}{ NOME DO EMPREENDIMENTO } & \multicolumn{1}{c}{ DISCURSO DOS EMPRESÁRIOS URBANOS } \\
\hline CENTRAL PARK CONDOMÍNIO CLUBE & "Amplo parque aquático e mais de 30 opç̃es de lazer e conforto" \\
L'ÁCQUA CONDOMINIUM CLUBE & "Tudo o que sua família sempre quis: mais de 40 itens de lazer, diversão garantida" \\
VITA RESIDENCIAL CLUB & "40 itens de lazer e espaço de sobra dentro e fora do seu apartamento" \\
VILA VERDE & "Muito verde e lazer para toda família" \\
CONDOMÍNIO CLUBE AQUARELLE & "Mais de 20 itens de lazer e um grande complexo de piscinas" \\
NOVO STILLO HOME CLUB & "Vista sua nova vida com lazer e conforto" \\
VILLA PARK & "2 áreas de lazer: uma no condomínio e outra no clube" \\
\hline
\end{tabular}

Fonte: Elaborado pelo autor com base em panfletos publicitários. 
Recife), a MRV (de Belo Horizonte), a Planc (de João Pessoa) - em parceria com a Gafisa (de São Paulo) -, o que já indica uma atração e valorização do mercado imobiliário de Natal:

Antigamente, as incorporadoras locais e a tipologia de Natal, você olha... é só um condomínio, um prédio, um condomínio bem pequeno, com uma piscina, no máximo um salão de festas. Quando as incorporadoras de fora vêm, elas trazem esse conceito de condomínio-clube, porque fazem grandes investimentos (informação verbal do entrevistado da Cyrela).

As incorporadoras locais também passaram a seguir essa tendência. Ecocil, G5, Estrutural, Capuche adotaram um comportamento mimético que propiciou o surgimento de uma convenção urbana, baseada no sucesso de vendas propiciado pelo valor agregado da nova tipologia:

Se eu lançar um empreendimento só como ele era feito nos anos $80 \ldots$ apartamento, vaga de garagem e uma quadra poliesportiva... é uma coisa. Mas se eu lanço um apartamento com um condomínio-clube... É claro que vai valorizar mais esses condomínios que têm todo esse lazer (informação verbal do entrevistado da Abreu Imóveis).

Embora, em alguns casos, a área privativa dos apartamentos dos condomínios-clube seja menor, acrescentar ao empreendimento um grande aparato de lazer foi a maneira encontrada de diversificar o produto residencial em Natal. Isso se dá porque tal tipologia se tornou tão disseminada hoje em dia que "se não tiver o clube, para a classe média não vende. Ou seja, um condomínio hoje para a classe média sem área de lazer, a pessoa não vai comprar. 0 lazer já é exigência da população (informação verbal do advogado especialista em mercado imobiliário)". Ainda acerca da inovação espacial, tal entrevistado revelou que:

Normalmente o novo empreendimento é um pouco melhor que aquele que foi construído. Então, com toda certeza, o empreendedor sabe que se ali tem um empreendimento com uma piscina, ele vai colocar uma piscina com uma quadra. E isso vai cada vez mais gerando clubes na redondeza, porque ele tem que ofe- recer mais (informação verbal do advogado especialista em mercado imobiliário).

Por serem empreendimentos de maior porte, são necessários grandes terrenos para a construção dos condomínios-clube. Nesse sentido, os entrevistados alegam que Natal é uma cidade pequena e que o Plano Diretor restringe o potencial construtivo de algumas áreas, além de existir grandes áreas que inviabilizam o crescimento do mercado imobiliário da cidade, tais como a grande quantidade de quartéis e instalações militares em bairros com infraestrutura consolidada, como Tirol e Lagoa Nova. A área de expansão de Natal em direção a Parnamirim é onde ainda se podem encontrar terrenos maiores, que possibilitam a construção dessa tipologia. Por isso,

é uma tendência que infelizmente Natal vai ter pouco, porque não tem área. Vai ficar tudo para Parnamirim, porque as áreas de Natal que estão sendo condomínios vão ser os últimos. Porque não tem onde a gente buscar mais áreas na cidade (informação verbal do entrevistado da Abreu Imóveis).

Além da existência de grandes terrenos, a legislação nessa parte da cidade também é responsável pela disseminação de condomíniosclube, uma vez que "em Parnamirim você pode comprar outorga onerosa, então você consegue construir até três vezes a área do terreno. Você paga uma taxa para a Prefeitura e possibilita aumentar o potencial construtivo" (informação verbal do entrevistado da Estrutural). Percebe-se que os índices urbanísticos são fundamentais para a localização dos condomínios-clube. Verticaliza-se ao máximo, com o potencial construtivo mais elevado, e equipam-se as áreas que restam.

Além de grandes terrenos, o grande porte de tais empreendimentos pode ser visto com relação ao significativo número de unidades construídas e o número de torres de edifícios. Toda essa estrutura só consegue ser construída se for "dividida perante 200, 300,400 [moradores]. Você não vai ter o condomínioclube para a classe AA, para 30 pessoas, porque sai muito caro" (informação verbal do advogado do ramo imobiliário entrevistado). Para conseguir arcar com os custos de construção de uma grande área de lazer, os empresários têm que repassá-los para um maior número de moradores, como forma de não tornar a taxa de condomínio tão elevada: "É claro que tem um 
custo a mais, porque antes você fazia só uma quadra e hoje vai fazer uma quadra, piscina, academia... tem um custo a mais, mas quando você rateia por um grupo grande é um valor que não é significante para o morador" (informação verbal do entrevistado da Abreu Imóveis).

Apesar da grande valorização do bairro de Nova Parnamirim, os empreendimentos lançados continuam sendo voltados para a classe média, uma vez que "o bairro não é um bairro de classe alta, não é um bairro nobre, então os lançamentos são voltados para uma classe que não tem um rendimento alto" (informação verbal do entrevistado da Procuradoria de Imóveis). Mais uma vez é evidente a importância das externalidades de vizinhança, em que o entorno não "comporta" um empreendimento diferente do padrão populacional existente. Por outro lado, não se constroem habitações do tipo "Minha Casa Minha Vida (MCMV)" porque "o preço do terreno é muito caro para você colocar unidades com valor agregado mais baixo" (informação verbal do entrevistado da Moura Dubeux). Existe, pois, uma relação direta entre o preço do terreno e a tipologia do imóvel, uma vez que o objetivo final dos empresários urbanos é, obviamente, o lucro.

De acordo com os entrevistados, pode-se observar que as justificativas de trânsito caótico e insegurança crescente são utilizadas para construir uma tipologia em que os moradores "possam usufruir de todas as áreas dentro do próprio empreendimento" (informação verbal do entrevistado da ECM Imóveis). Por outro lado, os condomínios-clube, por contarem com uma grande quantidade de unidades e, consequentemente, de moradores, acabam não se tornando tão atrativos para a população de maior renda, que prefere exclusividade. A maioria dos entrevistados afirma que não existem condomínios-clube nos bairros de elite devido à inexistência de grandes terrenos, porém alguns empresários urbanos revelam que tal tipologia não desperta o interesse da classe mais rica, uma vez que a população de alta renda não usa a estrutura de prédio, já que tem outras opções de lazer, além de não gostar de "morar com muita gente" e preferir apartamentos com área privativa maior.

Em geral, os entrevistados apontaram que o público-alvo a que são destinados os condomíniosclube é a classe média: "Casais recém-casados, com renda a partir de $\mathrm{R} \$ 6.000,00 \ldots$ de classe $\mathrm{B}$, com um ou dois filhos, que querem uma coisa mais moderna" (informação verbal do entrevistado da Estrutural). De acordo com tal representante, os estudos realizados pela empresa apontam que os consumidores que representam uma demanda potencial de compra de um empreendimento moram em um raio em torno de $15 \mathrm{~km}$ de proximidade do lançamento imobiliário. Fica claro que as inovações espaciais criadas por meio da abertura de novas localizações para atuação no mercado residencial ratificam o modelo de segmentação que já existe historicamente no processo de produção do espaço da cidade, uma vez que "uma das premissas da construção civil é observar o entorno" (informação verbal do entrevistado da Estrutural).

No que diz respeito às inovações no produto residencial, um dos entrevistados deixou claro que "a partir do momento que você põe uma coisa no mercado, o concorrente não vai pôr diferente. Senão ele vai estar inferior, defasado. Então todo mundo tem que acompanhar" (informação verbal do entrevistado da Diagonal/Rossi). A disseminação dessa inovação espacial para outras partes da cidade propicia uma homogeneização dos estoques habitacionais:

Quando o processo de difusão atinge um número de localizações maior do que a própria inovação atingia no início (devido às características de "transbordamento" espacial da difusão), pode-se concluir que a tendência à homogeneização prevalecerá (Abramo, 2007a, p. 311).

Enfim, pode-se perceber pelas entrevistas que os empresários urbanos conhecem muito bem a cidade de Natal. Tal conhecimento é usado para construir um lobby e direcionar o crescimento da cidade. A inovação espacial é uma constante reinvenção das estratégias de acumulação de capital, alterando a dinâmica espacial da cidade. 0 discurso dos empresários urbanos tende para um ponto comum, isto é, há uma convergência dos pensamentos e da prática dos agentes acerca da localização e das características de cada empreendimento. Como consequência imediata, tem-se uma homogeneização socioespacial em certos bairros, em detrimento do restante da cidade.

\section{Considerações finais}

A transformação do espaço urbano se dá por meio do que David Harvey chama de destruição 
criativa, estabelecendo uma relação direta entre a urbanização e a acumulação capitalista. Esse conceito, criado por Schumpeter, teve grande significado para o entendimento da lógica de atuação dos empresários capitalistas. No caso da configuração residencial, tal conceito foi utilizado como referência para Pedro Abramo designar as estratégias dos empresários urbanos, por meio de inovações espaciais. 0 movimento entre esses diferentes níveis de análise permitiu uma melhor compreensão das transformações espaciais.

A prática espacial da inovação permite realizar uma leitura acerca dos condomínios-clube. Em primeiro lugar, a inovação espacial caracteriza-se pela abertura de novas áreas para produção habitacional, possibilitando uma expansão do mercado imobiliário. No caso de Natal, pode-se destacar a localização de tais empreendimentos em uma área de expansão, que continha inúmeros terrenos, granjas e chácaras e tiveram seu uso modificado pelo intenso processo de verticalização. Em segundo lugar, a inovação caracteriza-se pela criação de novos produtos, como forma de se diferenciar dos estoques habitacionais existentes e proporcionar lucros maiores. Os condomínios-clube se diferenciam pela ênfase dada à estrutura de lazer e, por conseguinte, à qualidade de vida, como forma de desenvolver características peculiares que proporcionem lucros extras para os empresários urbanos. A venda de um novo estilo de vida é feita através do marketing e dos anúncios publicitários, que buscam disseminar a ideia de uma tipologia ideal de moradia, por meio da reprodução do discurso hegemônico dos empresários urbanos.

A difusão dessa estratégia de diferenciação, sendo atrativa para os compradores e lucrativa para os empreendedores, pode dar origem a uma configuração em que os estoques residenciais da cidade passem a apresentar características semelhantes. Essas características semelhantes são oriundas dos comportamentos miméticos dos empresários urbanos, que passam a copiar o modelo de sucesso para outros bairros da cidade, ou seja, através de um "contágio" desses valores e símbolos para os demais empreendimentos da cidade. Para Lefebvre, esses signos podem ser inseridos no âmbito das representações do espaço. Para Abramo, tal crença está arraigada em uma convenção urbana. No caso de Natal, os itens de lazer despontaram como carro-chefe dos lançamentos imobiliários e tornaram-se elementos de competição no marketing de venda dos condomínios.

0 apelo do marketing imobiliário baseia-se na criação de áreas comuns que representam espaços ideais de convivência, tranquilidade, segurança e qualidade de vida. Porém, uma das principais condições para a oferta de equipamentos de lazer é a aquisição de terrenos com dimensões acima de 10.000 metros quadrados para a implantação dos empreendimentos imobiliários. Essa estratégia se deve à possibilidade de maior verticalização oferecida sob essas condições, tornando os empreendimentos mais rentáveis. 0 fenômeno de proliferação dos condomínios-clube na Zona Sul de Natal tem diretamente a ver com a relação entre o potencial construtivo, a área do terreno e a possibilidade de verticalização, ou seja, quanto maior é o terreno, maior é a possibilidade de verticalizar e produzir adensamento, elevando assim a quantidade de unidades e a rentabilidade imobiliária, ao mesmo tempo liberando espaço para as estruturas do "clube". A associação desses atributos reforça a ideia de "clube", constituindo-se como tema preferencial da publicidade realizada pelo marketing imobiliário, para atrair uma demanda solvável.

Em Natal, observa-se que a estratégia de construção dessa nova tipologia residencial disseminou-se ao longo de importantes eixos viários da Zona Sul, em direção ao município de Parnamirim. Com relação aos bairros de elite de Natal, a tipologia condomínio-clube não está presente devido à ausência de grandes terrenos e, também, devido à preferência dos moradores de maior renda por um espaço privativo maior, isto é, por exclusividade. Como os condomínios-clube são construídos com muitas torres de edifícios e muitas unidades de apartamentos, inclusive por andar, isso não atrai a demanda mais rica. Por isso, sua localização se dá em áreas preferencialmente de classe média (bairros de status).

De maneira geral, verifica-se que a segmentação econômica promovida pelos empresários urbanos traz como consequência espacial a (auto)segregação alicerçada nos condomínios fechados, dos quais o condomínio-clube é a face mais nova desse fenômeno.

Com este trabalho, pretendeu-se contribuir para a compreensão desse fenômeno recente do mercado imobiliário que ocorre não apenas na cidade de Natal, mas também em outras cidades 
brasileiras. Dado que o tema é ainda pouco explorado, acredita-se que este trabalho sirva para dar suporte a outras pesquisas. Aqui, foi trabalhada a visão dos empresários urbanos. Pesquisas futuras podem ser realizadas também sobre, entre outros aspectos relevantes, a percepção dos próprios moradores sobre a importância do lazer na escolha residencial, as relações de sociabilidade produzidas intramuros e a autosegregação residencial.

\section{Referências}

Abramo, P. (1995). A regulação urbana e o regime urbano: a estrutura urbana, sua reprodutibilidade e o capital. Ensaios FEE, 16(2):510-555.

Abramo, P. (2007a). A cidade caleidoscópica: coordenação espacial e convenção urbana - uma perspectiva heterodoxa para a economia urbana. São Paulo: Bertrand Brasil.

Abramo, P. (2007b). A cidade COM-FUSA. Revista Brasileira de Estudos Urbanos e Regionais, 9(2), 25-54.

Campos, I. M. (2007). A epidemia dos Condomínios-Clubes. São Paulo: Instituto Brasileiro de Desenvolvimento da Arquitetura. Recuperado em 29 de julho de 2011, de http://www.forumdaconstrucao.com.br/conteudo. php?a=33\&Cod $=61$.

Carlos, A. F. A. C. (1999). O espaço urbano: novos escritos sobre a cidade. São Paulo: Contexto.

Clementino, M. L. M. (1995). Economia e Urbanização: o Rio Grande do Norte nos anos 70. Natal: UFRN.

Correa, R. L. (1995). O espaço urbano. São Paulo: Ática.

Costa, A. A. (2000). A verticalização e as transformações do espaço urbano de Natal/RN (Tese de doutorado). Universidade Federal do Rio de Janeiro, Rio de Janeiro.

Ferreira, Â. L. A. (1996). De la produccion del espacio urbano a la creación de territorios en la ciudad: un estudio sobre la constitucion de lo urbano en Natal, Brasil. (Tese de doutorado). Universidade de Barcelona, Barcelona.

Furtado, E. M. (2007). 0 turismo na capital potiguar: visões sobre o espaço urbano de Natal/RN. Mercator - Revista de Geografia da UFC, 6(11), 51-58.

Guerra, M. F. (2013). Vende-se qualidade de vida: Alphaville Barueri - implantação e consolidação de uma cidade privada (Dissertação de mestrado). Universidade de São Paulo. São Paulo.

Harvey, D. (1989). The urban experience. Oxford: Basil Blackwell.

Harvey, D. (1996). Condição pós-moderna: uma pesquisa sobre as origens da mudança cultural. São Paulo: Edições Loyola.

Harvey, D. (2005). A produção capitalista do espaço. São Paulo: AnnaBlume.

Instituto Brasileiro de Geografia e Estatística - IBGE (2010). Censo Demográfico - 2010. Recuperado em 20 de agosto de 2011, de http://www.ibge.com.br.

Lefebvre, H. (2008). A revolução urbana. Belo Horizonte: Editora UFMG.

Medeiros, S. R. F. Q. (2007). A casa própria: sonho ou realidade? - Um olhar sobre os conjuntos habitacionais em Natal. (Dissertação de mestrado). Universidade Federal do Rio Grande do Norte, Natal.

Natal. Prefeitura. Secretaria Municipal do Meio Ambiente e Urbanismo - SEMURB. (2010). Anuário Natal 2010. Natal.

Nobre, P. (2001). Entre o cartão-postal e a cidade real: um estudo sobre paisagem e produção imobiliária em Natal/ $R N$ (Dissertação de mestrado). Universidade Federal do Rio Grande do Norte, Natal

Oliveira, R. M. P., Vianna, A. A., Borges, A. H., Teixeira, R. B., \& Silva, H. A. (2010). A sustentabilidade anda por um fio: instauração, retrocesso e perspectivas da reforma urbana em Natal. In Anais do Congresso Internacional Sustentabilidade e Habitação de Interesse Social. Porto Alegre: PUCRS.

Parnamirim. Prefeitura. Secretaria Municipal do Meio Ambiente e do Desenvolvimento Urbano da Prefeitura de Parnamirim. (2010). Dados de licenciamento do município de Parnamirim entre os anos de 2008 e 2010. Disponível em meio digital para a base de pesquisa Unidade Interdisciplinar de Estudos sobre Habitação e o Espaço Construído.

Sampaio, G. B. D. A. (2009). Condomínios verticais residenciais na cidade de São Paulo (2000-2008): condomínios-clube (Dissertação de mestrado). Universidade Presbiteriana Mackenzie, São Paulo.

Schumpeter, J. A. (1984). Capitalismo, socialismo e democracia. Rio de Janeiro: Zahar. 
Silva, A. F. C. (2010). O litoral e a metrópole: dinâmica imobiliária, turismo e expansão urbana na região metropolitana de Natal-RN (Tese de doutorado). Universidade Federal do Rio Grande do Norte, Natal.

Smith, N. (1984). Desenvolvimento desigual. Rio de Janeiro: Bertrand Brasil.

Turra, M. (2003). Estado, expansão urbana e acumulação de capital: os financiamentos da CEF em Nova Parnamirim e Emaús (1995-2002) (Dissertação de mestrado). Universidade Federal do Rio Grande do Norte. Natal.
Valença, M. M. (2006). Cidades ingovernáveis? Ensaio sobre o pensamento harveyano acerca da urbanização do capital. In J. B. Silva, L. C. Lima, \& D. Elias (Orgs.), Panorama da geografia brasileira. São Paulo: Annablume.

Valença, M. M. (2008). Ensaio sobre a dinâmica imobiliária do imobiliário em Harvey. In M. M. Valença (Org.), Cidade (i)legal. Rio de Janeiro: Mauad X.

Recebido: Mar. 23, 2014

Aprovado: Set. 17, 2014 